\title{
Atual currículo de matemática do estado de São Paulo: Indicações para a introdução do ensino da ideia de irracionalidade
}

\author{
Angélica da Fontoura Garcia Silva \\ Professora, Universidade Bandeirante Anhanguera/SP \\ angelicafontoura@gmail.com
}

\section{Ruy Cesar Pietropaolo}

Professor, Universidade Bandeirante Anhanguera/SP

rpietropaolo@gmail.com

\section{Tania Maria Mendonça Campos}

Professora, Universidade Bandeirante Anhanguera/SP

taniammcampos@gmail.com

\section{Resumo}

Este estudo tem como finalidade analisar os pressupostos e diretrizes que alicerçam o atual currículo de Matemática proposto para o Estado de São Paulo, Brasil, no que se refere à introdução do conceito de irracionalidade. Buscamos identificar a relação das indicações propostas pelo movimento de implementação curricular e outras orientações e pesquisas que abordam a mesma temática. Trata-se de uma investigação bibliográfica/documental na qual analisaremos o material de apoio denominado "Caderno do Professor", sob a luz tanto de teorias que versam sobre o currículo como também de alguns estudos que investigam o objeto matemático Números Irracionais. Examinando os documentos oficiais no âmbito mais geral, observamos certa preocupação com a "Enculturação Matemática" proposta por Bishop (1997), todavia verificamos também algumas lacunas nas orientações a respeito da incomensurabilidade e densidade na reta.

Palavras-chave: Educação Matemática; Implementação de inovações curriculares; Ensino e aprendizagem; Números irracionais; Professores que ensinam matemática.

\section{Current curriculum mathematics of São Paulo: Indications for the introduction of teaching idea of irrationality}

\begin{abstract}
This study aims to analyze the foundations and guidelines which current support the Mathematics syllabus suggested for the state of São Paulo in Brazil, regarding the introduction of irrationality as a concept. We tried to identify the relation between the suggestions as proposed by the syllabus implementation and other perspectives and researches that work with the same subject. This is a bibliographical/ documental study in which we will analyze the supporting resource called "Teacher's Book" both under the perspective of syllabus theories and of some studies which focus on the Mathematical subject "Irrational Numbers". By examining official syllabi papers in a general scope, we noticed some attention was given to Bishop's Mathematical Enculturation (1997), although we also found gaps in the guidelines regarding incommensurability and line segment density.
\end{abstract}

Keywords: Mathematics teaching; Implementation of syllabus innovation; Teaching and learning; Irrational numbers; Tutors teaching Mathematics. 


\section{Introdução}

Neste artigo temos por finalidade apresentar os resultados de pesquisa documental, na qual procuramos analisar as orientações contidas nos Parâmetros Curriculares Nacionais (PCN) e no currículo prescrito para o Estado de São Paulo, Brasil, desde o ano de 2008, sobre a abordagem dos números irracionais para os anos finais do Ensino Fundamental. Em nosso estudo procuramos examinar os pressupostos e diretrizes que alicerçam o atual currículo de Matemática no que se refere à introdução do conceito de irracionalidade, com o objetivo de identificar a relação das indicações propostas pelo movimento de implementação curricular e outras orientações e pesquisas que tratam da mesma temática.

Para delimitar nosso problema de pesquisa, apresentaremos a relevância do tema, a fundamentação teórica que utilizamos em nossa análise, os pressupostos dos PCN e do Currículo Oficial do Estado de São Paulo e sua relação com os estudos que vêm sendo desenvolvidos a respeito dos números irracionais. Em seguida, exporemos nossa análise, as considerações finais e as perspectivas futuras.

\section{Relevância e Fundamentação Teórica}

Inicialmente, cabe salientar a importância do estudo dos números irracionais para a compreensão do processo de ampliação do conceito de número, ao longo da Educação Básica.

No tocante ao objeto matemático irracionalidade, observamos a existência de diversas pesquisas relacionadas aos problemas tanto com seu ensino quanto com sua aprendizagem. Fischbein, Jehiam e Cohen (1995), por exemplo, pesquisaram os conhecimentos sobre os números irracionais em alunos que estudavam nos anos finais da Educação Básica (alunos com 14 ou 15 anos) e futuros professores de matemática. Os autores encontraram como principal dificuldade dos sujeitos investigados a falta de compreensão dos conceitos dos diferentes conjuntos numéricos e especialmente, do conjunto numérico irracional (FISCHBEIN et al., 1995, p. 43).

Assim como Fischbein et al. (1995), Sirotic (2004), que também pesquisou o conhecimento de futuros professores a respeito de números irracionais, verificou que os conhecimentos dos sujeitos investigados eram os mesmos dos alcançados ao longo do ensino secundário.

Quanto às pesquisas desenvolvidas no Brasil sobre a temática, é importante destacar estudos como os de Corbo (2005). A autora, ao procurar possibilidades de explorar a seção áurea como contexto para o desenvolvimento de noções relativas à incomensurabilidade de segmentos de reta em alunos do último ano de Licenciatura em Matemática, observou que eles ainda não dominavam noções fundamentais para 
a compreensão desse conjunto numérico. Corbo (2005) verificou, por exemplo, que muitos dos futuros professores investigados definiram segmentos incomensuráveis como segmentos que não podem ser medidos. Tais dificuldades também são discutidas em documentos oficiais, como o currículo oficial de matemática proposto para o Estado de São Paulo.

Ademais, ao observarmos resultados de avaliações do conhecimento matemático de professores, percebemos que no Brasil e, em particular, no Estado de São Paulo, o conhecimento específico dos números irracionais está muito longe do ideal.

Os resultados de uma prova realizada por professores, titulares de cargo, da rede pública estadual paulista, em 2010, mostram que em algumas questões que envolvem números irracionais, os docentes tiveram um percentual de acertos muito baixo. Para exemplificar, apresentamos uma situação-problema na Figura 1 que pretendia avaliar a habilidade de compreender e construir o significado das operações com os números irracionais:

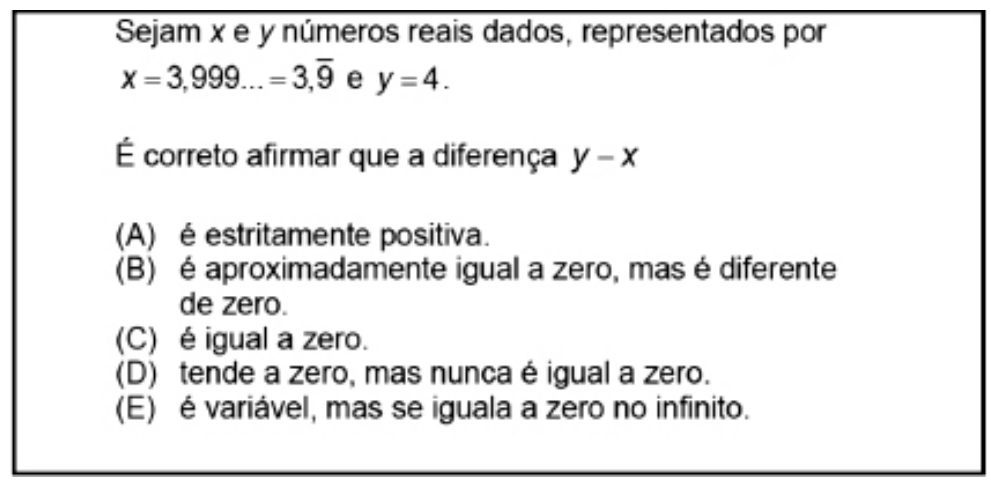

Figura 1 - Questão da prova Promoção por mérito (SÃO PAULO, 2010)

Trata-se de questão exemplar, provavelmente foco de discussão nos cursos de licenciatura e que poderia ter um bom percentual de acertos. Todavia, essa foi a questão que apresentou a taxa mais baixa de acerto de toda prova, com índice de $12 \%$.

Portanto, a análise de tais dificuldades nos preocupa, uma vez que estudos como os de Shulman (1987) consideram a importância do conhecimento do conteúdo, enfatizando que o domínio deste é imprescindível para o ensino de toda e qualquer disciplina.

Enfim, analisando as pesquisas apresentadas, há indícios de que esse conceito tão importante não está sendo desenvolvido e compreendido como deveria nos cursos de licenciatura, e, portanto, a divulgação de estudos que discutam essa temática pode ser de fundamental importância na formação docente. 
Sobre uma possível relação intrínseca entre o processo de inovação curricular e a formação docente, concordamos com Pietropaolo (2002). Para o autor tais orientações poderiam

[...] nortear a formação inicial e continuada de professores, pois à medida que os fundamentos do currículo se tornem claros fica implícito o tipo de formação que se pretende para o professor, como também orientar a produção de livros e de outros materiais didáticos, contribuindo dessa forma para configuração de uma política voltada a melhoria do ensino fundamental (PIETROPAOLO, 2002, p. 37).

Nesse contexto, observamos no estado de São Paulo, um cenário que pode favorecer o processo de formação profissional docente. Assim torna-se fundamental que em nossa análise identifiquemos se os documentos divulgados nas orientações curriculares levaram em conta ou não resultados de pesquisas sobre os processos de ensino e aprendizagem dos números irracionais

Quanto aos pressupostos que embasam o currículo, apoiamo-nos nos princípios da Educação Matemática escolar como processo de "enculturação" proposto por Bishop (1997), o qual considera que o currículo deve estar relacionado aos valores da cultura que se pretende disseminar. Para o autor, a "enculturação matemática" consiste em envolver também conhecimentos ligados a cultura matemática, ou seja, considera que o processo de ensino e aprendizagem da matemática pode desenvolver valores que se relacionam a este saber específico. Enfim, para Bishop (1997), "Enculturação Matemática” trata do incentivo de formas de pensar, agir e sentir, próprias das atividades matemáticas desenvolvidas pelas diferentes culturas, e que precisam ser disseminadas. Seus estudos apontam a necessidade de que os currículos de Matemática incluam um enfoque cultural caracterizado a partir de cinco princípios básicos, a saber:

- Princípio da Representatividade: este princípio demanda que toda ação visando o ensino deve representar adequadamente a Matemática como um legítimo componente cultural; ou seja, implica em incorporar e, explicitar valores da cultura matemática como área de conhecimento no processo de ensinar e aprender Matemática.

- Princípio da Acessibilidade: a Matemática escolar deve ser acessível a todos os alunos; não privilegiando apenas os estudantes mais aptos a seguir estudos mais aprofundados; o currículo concebido e praticado não pode estar além das capacidades intelectuais dos alunos. 
- Princípio do Poder Explicativo: considera a Matemática como fenômeno cultural, uma fonte de justificativas de situações presentes no cotidiano. A explicação não pode aparecer apenas como forma de "fazer", mas também - e principalmente - como forma de "explicar" e "conhecer". A resolução de problemas deve ser explorada, e devem-se propor problemas que tenham significado para os alunos ou que possam vir a ser explicados por eles; consequentemente, o ambiente dos alunos deve ser explorado.

- Princípio do Formalismo: deve objetivar o trabalho no nível formal da Cultura Matemática, conectando-se com o nível informal e oferecendo introdução ao nível técnico. Pressupõe o trabalho com situações que corroborem ou conflitem com conhecimentos anteriores forçando uma ressignificação dos objetos matemáticos e ampliando seus horizontes de aplicação, em um processo no qual as propriedades e descrições formais dos objetos são a ultima forma de identificação de seus significados concretos e dos conceitos que encerram.

- Princípio da Visão Ampla e Elementar: pressupõe que o trabalho com os conceitos matemáticos em sala de aula devem levar em conta um amplo leque de fenômenos de modo a realizar as conexões necessárias. Assim, a amplitude de fenômenos e assuntos abordados implica em uma visão elementar destes assuntos de modo que o aluno tenha a "visão do todo" e compreende os conceitos elementares. Não pode ser requerido um nível alto de especialização.

Logo, os estudos de Bishop (1997) apontam para o fato de que os currículos deveriam apresentar o processo de "enculturação" do saber matemático.

Diante do exposto, neste estudo pretendemos efetuar a análise das orientações oficiais apresentadas para os PCN e o novo currículo oficial proposto para o Estado de São Paulo à luz das pesquisas que tratam das dificuldades encontradas nos processos de ensino e de aprendizagem do conceito da irracionalidade e ao conceito de "enculturação" do saber matemático. Para examinar o novo currículo oficial de São Paulo utilizaremos o Caderno do Professor. ${ }^{1}$

Como metodologia, este estudo se apoia em uma pesquisa documental/bibliográfica com a finalidade de analisar os pressupostos e diretrizes que alicerçam o atual currículo de Matemática proposto para o Estado de São Paulo, Brasil, no que se refere à introdução da irracionalidade. Investigamos estudos e pesquisas que tratam da temática, as orientações contidas nos documentos que orientam as práticas pedagógicas de professores da rede estadual de São Paulo.

1. Cadernos do Professor - materiais de apoio ao currículo contendo indicações ao professor. 


\section{Recentes Reformas Curriculares para o Ensino de Matemática: pressupostos e diretrizes para introdução do conceito de números irracionais}

Tomamos como marco para este estudo os PCN em âmbito nacional e o Novo Currículo Oficial do Estado de São Paulo proposto a partir do ano de 2008. Assim sendo, apresentaremos a seguir os pressupostos e indicações para o ensino de números irracionais propostos por esses dois documentos.

\section{Brasil: Parâmetros Curriculares Nacionais}

A elaboração dos PCN surge no bojo de mudanças substanciais na política brasileira. Esse documento é construído a fim de consolidar as indicações presentes na LDBEN $^{2}$ n. ${ }^{\circ}$ 9.394/1996, em relação ao conjunto de diretrizes capazes de nortear os currículos e conteúdos mínimos.

No tocante às orientações apresentadas nestes documentos sobre a abordagem dos irracionais nas séries finais do Ensino Fundamental, um dos objetivos para o ensino de Matemática é o desenvolvimento do pensamento numérico por meio de situações-problema envolvendo diferentes conjuntos numéricos e, dentre eles, o conjunto dos números irracionais, de forma a: “[...] ampliar e consolidar os significados dos números racionais a partir dos diferentes usos em contextos sociais e matemáticos e reconhecer que existem números que não são racionais" (BRASIL, 1998, p. 81).

Este mesmo documento indica que o estudo dos números irracionais, apesar de ocupar um tempo considerável das aulas de Matemática nos anos finais, "têm se limitado quase que exclusivamente ao ensino do cálculo com radicais" (BRASIL, 1998, p. 106). Além disso, ainda segundo estas mesmas orientações, esse foco "pouco tem contribuído para que os alunos desenvolvam seu conceito" (BRASIL, 1998, p. 106).

Chamam ainda a atenção para o fato de que historicamente a existência e caracterização desse conjunto numérico não foram aceitas com facilidade, e que sua sistematização é um tanto recente, a qual, o que, segundo seus autores, podem dificultar os processos de ensino e de aprendizagem. Tais orientações identificam ainda outras dificuldades, não menos importantes, como a de encontrar situações do cotidiano para iniciar seu ensino. A noção de densidade do conjunto dos racionais na reta numérica é outra dificuldade apontada.

Sugere, também, a inter-relação entre Números, Grandezas e Medidas e Geometria, sugerindo que estabeleçam a razão entre: a medida do comprimento de uma circunferência e seu diâmetro; da diagonal e a medida do lado de um quadrado e a relação entre as medidas do perímetro e do diâmetro de um círculo.

2. LDBEN - Lei de Diretrizes e Bases da Educação Nacional. 
Tais propostas são acompanhadas de sugestões, por exemplo, quando apresenta a possibilidade de introduzir o conceito de irracionalidade por meio de uma situação em que se destaque a necessidade de ampliação do conjunto dos racionais, utilizando-se de "um problema clássico", qual seja:

[...] encontrar o comprimento da diagonal de um quadrado, tomando o lado como unidade, que conduz ao número $\sqrt{2}$. Nesse caso, pode-se informar (ou indicar a prova) da irracionalidade de $\sqrt{2}$, por não ser uma razão entre inteiros. O problema das raízes quadradas de inteiros positivos que não são quadrados perfeitos, $\sqrt{3}, \sqrt{5}$ etc., poderia seguir-se ao caso particular de $\sqrt{2}$ (BRASIL, 1998, p. 106).

Assim sendo, observa-se que este documento apresenta indicações para que o docente apresente uma prova formal da irracionalidade de $\sqrt{2}$.

Quanto à apresentação do número $\pi$, o documento de orientação sugere que uma prática de experimentação por meio da observação da regularidade nos quocientes entre as medidas do comprimento e do diâmetro de uma variedade de circunferências pode se traduzir em dificuldades na aceitação do número $\pi$ como irracional. Sugerem duas alternativas: efetuar os cálculos segundo as regras operacionais análogas às que são válidas para os racionais ou por aproximação com o auxílio de calculadora. Entretanto, notamos que o uso do recurso calculadora tem limitações nos dígitos, gerando assim apenas aproximações racionais do número $\pi$, o que poderá acarretar a concepção errônea por parte do aluno de que $\pi$ é racional.

\section{São Paulo: Currículo de Matemática proposto a partir de 2008}

Depois da elaboração dos PCN, somente a partir do ano letivo de 2008 que se observaram proposições de mudanças curriculares para a rede estadual de ensino de São Paulo. A Secretaria de Estado da Educação (SEE) indica um novo currículo, que desde o ano anterior vinha sendo anunciado como a Nova Proposta Curricular para o Ensino Fundamental - Ciclo II e Médio do Estado de São Paulo. Tal reforma conta também com materiais instrucionais denominados Caderno do Professor (CP) e Caderno do Aluno (CA).

Em uma primeira análise notamos que o elenco de conteúdos do Ensino Fundamental não se diferencia de forma substancial do que culturalmente é ensinado para este nível de ensino. O currículo de matemática é organizado nesse documento em três grandes blocos temáticos denominados: Números, Geometria e Relações, cujos conteúdos se interpenetram permanentemente, numa espécie de "interdisciplinaridade interna" da própria disciplina (São Paulo, 2010). 
Observa-se que nas diretrizes apresentadas no atual currículo há uma incorporação dos objetivos de documentos oficiais brasileiros, tanto os nacionais como os estaduais. No âmbito federal há uma incorporação de ideias como a exploração dos significados, preocupação com uma formação mais completa do aluno, salientando o papel do desenvolvimento de "atitudes"3 que devem estar presentes nos currículos e reforçando a centralidade no aluno e, por conseguinte, nos processos de ensino e aprendizagem.

As orientações contidas no material de apoio (Caderno do Professor) se propõe a explorar "ideias fundamentais" no desenvolvimento das diferentes temáticas, ou seja, proporcionalidade, equivalência, ordem e aproximação, as quais detalharemos a seguir.

A ideia de proporcionalidade, por exemplo, apresenta-se, em geral, no raciocínio analógico e é encontrada no estudo das frações, razões e proporções, estudo da semelhança de figuras, grandezas diretamente proporcionais que guia todo o trabalho com funções do primeiro grau. Observamos que essa ideia é o foco da introdução do conceito de irracionalidade.

No material de apoio, apresentado pela SEE, os autores propõem para alunos de 12 anos uma abordagem do conteúdo por meio da proposição de situações que possibilitem a eles o contato com raízes não exatas e em atividades experimentais, que envolvem a proporcionalidade entre o lado e a diagonal de quadrados, utilizando régua e calculadora para obter valores aproximados. É importante salientar que tais orientações sugerem tal procedimento, mas sem que o professor faça menção aos irracionais.

\section{Proporcionalidade no quadrado}

2. Na malha quadriculada a seguir, desenhe 3 quadrados de lados iguais a $2 \mathrm{~cm}, 3 \mathrm{~cm}$ e $6 \mathrm{~cm}$, respectivamente. Em cada um deles, trace uma diagonal ligando dois vértices opostos. Meça com uma régua o comprimento das diagonais obtidos e registre os valores na tabela. Em seguida, calcule a razão entre as medidas da diagonal e do lado de cada quadrado.

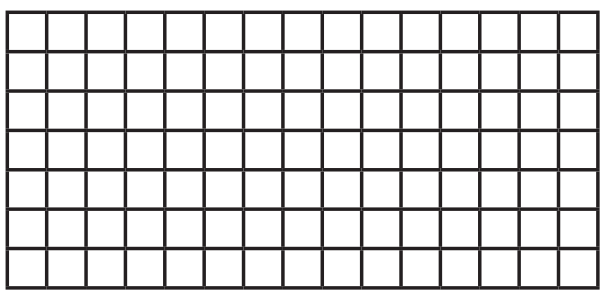

3. O sentido dado ao termo Atitudes é o mesmo adotado pelos Parâmetros Curriculares Nacionais (1998) de Matemática para o Ensino Fundamental quando explicitam objetivos tais como: levar o aluno a sentir-se seguro da própria capacidade de construir conhecimentos matemáticos, desenvolvendo a auto-estima e a perseverança na busca de soluções; predispor-se à utilização de conhecimentos matemáticos como recursos para interpretar, analisar e resolver problemas em contextos diversos. 


\begin{tabular}{|l|l|l|l|}
\hline Quadrado & $\begin{array}{l}\text { Lado }(l) \text { em } \\
\text { cm }\end{array}$ & $\begin{array}{l}\text { Diagonal }(d) \\
\text { em cm }\end{array}$ & Razão $\frac{d}{l}$ \\
\hline $\mathrm{Q}_{1}$ & & & \\
\hline $\mathrm{Q}_{2}$ & & & \\
\hline $\mathrm{Q}_{3}$ & & & \\
\hline
\end{tabular}

a) Duplicando a medida do lado a da diagonal também duplica?

b) E triplicando a medida do lado?

c) Há proporcionalidade entre a diagonal e o lado dos quadrados?

d) A razão obtida entre a diagonal e o lado desses quadrados se aproxima de qual dos números:

$\sqrt{2}, \sqrt{3}$ ou $\sqrt{5}$ (observação: você pode utilizar a calculadora para obter uma aproximação)

Figura 2 - Questão do Caderno do Aluno $6 .{ }^{a}$ série/7. ${ }^{\circ}$ ano (SÃO PAULO, 2009a, pp.27-8)

Assim como a tarefa destacada na Figura 2, são propostos aos estudantes outros experimentos por meio de medições com a finalidade de apresentar-lhes os números irracionais. Tal fato é mencionado nas orientações contidas no Caderno do professor no qual consta uma afirmação de que tal sequência tem em comum o fato de esses números não poderem ser gerados por uma divisão entre inteiros (SÃO PAULO, 2009a, p. 31-39).

Enfim, analisando o desenvolvimento desses conteúdos, notamos que, mesmo havendo um temário próximo ao que é, em geral, desenvolvido em atividades de sala de aula, existe uma busca de aproximação entre o conteúdo escolar e o universo da cultura matemática. Ou seja, utiliza-se aqui o princípio da Representatividade de Bishop nos Currículo de Matemática, pois seria um importante componente da cultura Matemática como área do saber. Além disso, esse tema permite estabelecer conexões entre os diferentes blocos em que se organiza o currículo de Matemática como Números, Geometria e Grandezas e Medidas. Tendo em conta essas orientações, pensamos que um dos aspectos dos números irracionais que permitiria a conexão entre blocos distintos de conteúdos é o que envolve a incomensurabilidade de grandezas - interpretação geométrica dos números irracionais. Como exemplo, o estudo do Teorema de Tales, proposto inicialmente como atividade experimental, poderia posteriormente avançar para a discussão sobre o caso que envolve segmentos incomensuráveis.

Para complementar nossa análise, apresentamos de forma um pouco mais detalhada as orientações contidas nos cadernos referentes ao 9. ${ }^{\circ}$ ano do Ensino Fundamental, que contêm orientações específicas para a introdução e o desenvolvimento do conceito de número irracional. 


\section{Cadernos do 9. ${ }^{\circ}$ ano do Ensino Fundamental}

As orientações destinadas ao professor sugerem ampliar os conjuntos numéricos explorando inicialmente a representação de conjuntos por meio de diagramas de Venn. Observamos que o foco do trabalho está na estrutura algébrica desses conjuntos.

Para o desenvolvimento do conceito de irracionalidade, as orientações contidas no Caderno do Professor propõem ao docente iniciar os estudos por meio da ideia de incomensurabilidade. Segundo tais orientações:

Nem toda medida pode ser expressa na forma de uma razão entre números inteiros. A descoberta da existência dos segmentos incomensuráveis foi um dos fatos mais surpreendentes da história da Matemática. Um dos exemplos mais conhecidos de incomensurabilidade é a medida da diagonal do quadrado em relação ao lado, que foi atribuída aos pitagóricos, na Grécia Antiga (SÃO PAULO, 2009, p. 19).

Tais recomendações são acompanhadas de orientações didáticas postas sob a intenção de contribuir para a reflexão sobre como ensinar, contendo uma análise de parte dos conceitos e procedimentos indicados e considerações sobre como esse conhecimento é elaborado ou construído pelos alunos. Por exemplo, sobre a atividade de obtenção da medida da diagonal de um quadrado de lado unitário, complementando considerações a respeito da inadequação de um tratamento formal dos irracionais nesta etapa da escolaridade, os autores observam que

Nesse caso, pode-se informar (ou indicar a prova) da irracionalidade de $\sqrt{2}$, por não ser uma razão de inteiros. O problema das raízes quadradas de inteiros positivos que não são quadrados perfeitos $\sqrt{3}, \sqrt{5}$ etc., poderia seguir-se ao caso particular de $\sqrt{2}$. (ibid., p.106).

Não se faz, todavia, referência a segmentos incomensuráveis, ao longo do texto e também quando os autores aludem à razão entre a diagonal e o lado de um quadrado qualquer, não há menção à incomensurabilidade desses dois segmentos. Esse tema exigiria um tratamento formal que - interpretamos, nós segundo a abordagem sugerida neste documento, se configura prematuro, nesta fase da escolaridade.

Conceitos importantes apresentados no Caderno do Professor, e com uma justificativa discutível, são os de números algébricos e transcendentes. Os autores apresentam e esclarecem que essa seria uma forma de 
[...] justificar para o aluno a diferença entre números irracionais como $\sqrt{2}$ e o $\pi$. Enquanto $\sqrt{2}$ é um número irracional algébrico, não há uma equação algébrica com coeficientes inteiros que tenha como solução o número $\pi$, o que o caracteriza como irracional não algébrico (irracional transcendente: quando um número real não é algébrico dizemos que ele é transcendente). Todo número racional é algébrico, mas nem todo número irracional é algébrico (SÃO PAULO, 2009, p. 34).

Nesse caso, os autores sugerem que os alunos apenas reconheçam o número irracional $\pi$. Diante do exposto - no que diz respeito ao conjunto dos números irracionais -, reputamos que as orientações contidas nos Cadernos do Professor apresentam um conjunto de ideias que já são consideradas nos documentos anteriores, como os Parâmetros Curriculares Nacionais.

Afigura-se-nos também que as indicações contidas nesse material levam em conta alguns dos estudos ocorridos na Educação Matemática, todavia há de considerar que essa proposta de abordagem no curso do último ano do Ensino Fundamental, por exemplo, o conceito de irracionalidade, a nosso ver, não foi explorado em sua plenitude.

\section{Síntese das análises dos documentos oficiais}

Analisando os documentos oficiais no âmbito mais geral - PCN e novo currículo oficial de São Paulo/2008 -, observamos que há certa preocupação com a "Enculturação Matemática” proposta por Bishop (1997). No entanto, deve-se observar que não há, no documento analisado, menções explícitas a respeito da adoção de todos esses princípios da Enculturação.

No tocante às orientações relativas ao processo de ensino e de aprendizagem dos números irracionais contidas no PCN e no novo Currículo de Matemática de São Paulo, consideramos que nem todos os princípios da Enculturação, propostos por Bishop (1997), foram contemplados, sobretudo os relativos à Acessibilidade, ao Formalismo e à Concepção Ampla e Elementar.

Em relação à Acessibilidade, observamos foco no aluno: "a Matemática, nos currículos, está bem longe de representar um conteúdo destinado apenas a especialistas ou as pessoas com dons especiais" (SÃO PAULO, 2008, p. 44). Apesar disso, não constatamos que haja tal compreensão por parte dos professores. Diversos estudos, como os de Rodrigues (2010), Dantas (2010) e Grenchi (2011), indicam que os professores consideram que muitas das orientações relativas aos números irracionais são inacessíveis aos alunos. Grenchi (2011), por exemplo, - que desenvolveu um estudo exploratório mediante a coleta de dados por meio de um questionário, respondido 
por 36 professores que lecionavam em escolas estaduais de um município paulista -, observou que, nos conteúdos apresentados nos documentos de apoio "Caderno dos Alunos", "[...] grande parte dos professores considera que os mesmos são insuficientes para a aprendizagem dos alunos" (GRENCHI, 2011, p. 109).

Atender ao formalismo, que pressupõe que o nível formal da Cultura Matemática deve conectar-se com o nível informal de modo a favorecer uma ressignificação dos números irracionais, não é uma tarefa fácil, sobretudo se levarmos em conta sua não-necessidade para resolver situações simples de medidas e cotidianas dos alunos. De fato, esse tema exigiria um tratamento formal que - interpretamos - segundo a abordagem sugerida nos documentos curriculares, se configura prematuro, nesta fase da escolaridade.

Observamos, assim, que há uma lacuna no que concerne ao estudo dos números irracionais, o que nos parece preocupante, pois esta é uma etapa importante para o entendimento da ampliação dos campos numéricos. Nestas orientações, percebemos que o tema surge restrito a sua identificação no cálculo da razão entre medidas de alguns poucos pares de segmentos incomensuráveis, sem discutir o real significado dessa noção.

Por outro lado, os autores do documento de São Paulo esclarecem que as orientações oferecidas não contemplam todos os aspectos relacionados aos números irracionais a serem desenvolvidos no Ensino Fundamental II. Ou seja, a Concepção Ampla e Elementar de Bishop, não estaria contemplada no documento, pois esses autores pouco discutem a questão da incomensurabilidade de grandezas e se aprofundam, por exemplo, nas discussões sobre o conceito de frações contínuas - que historicamente não é proposto para o Ensino Fundamental. Apesar disso, vale ressaltar que as orientações contidas nos documentos analisados indicam que cabe ao professor a tarefa de organizar os conteúdos de forma a estabelecer as conexões possíveis e definir o grau de aprofundamento. Assim, entendemos que há indícios, nesses documentos, de preocupação com uma abordagem ampla e elementar do saber matemático. No entanto, essa abordagem não é consolidada para o ensino dos irracionais.

Assim sendo, ao examinar as orientações para o trabalho com os números irracionais, nos documentos oficiais mencionados, configurando-se tal deficiência, acreditamos que poderão faltar aos professores vivências que lhes poderiam permitir a compreensão desse conteúdo. Fato já comprovado por Dantas (2010), quando este analisou um fórum de um curso que discutia questões relacionadas ao tema. $\mathrm{O}$ autor observou, por exemplo, a falta de conhecimento dos professores sobre conceitos referentes à inter-relação entre geometria e os números irracionais, pois encontraram dificuldades para selecionar, resolver e explorar problemas envolvendo essas temáticas.

Esse autor identificou ainda, nestes professores, uma forte tendência de reduzir o estudo dos números irracionais apenas aos cálculos envolvendo radicais. Corbo (2012) afirma que os professores envolvidos em sua pesquisa consideram que seria 
suficiente, para a Educação Básica, uma abordagem introdutória dos irracionais, que envolvesse apenas representações e cálculos com radicais.

Por fim, é importante salientar que os resultados apresentados por este nosso estudo não envolveram a análise in loco das práticas dos professores que vivenciam movimentos de reformulação curricular. Portanto, consideramos a necessidade de que se realizem novos estudos que examinem a prática pedagógica do professor ao ensinar a introdução do conceito de números irracionais quando imerso neste contexto de reforma de currículo.

\section{Referências}

BISHOP, Alan J. Mathematical Enculturation: a cultural perspective on Mathematics Education. 3. ed., Dordrecht: Kluwer Academic Publishers, 1997.

BRASIL. Ministério da Educação. Secretaria de Educação Fundamental. Parâmetros Curriculares Nacionais para o Ensino Fundamental: Introdução. Brasília, DF: MEC/SEF, 1997.

Secretaria de Educação Fundamental. Parâmetros Curriculares Nacionais: Terceiro e Quarto Ciclos do Ensino Fundamental: Matemática. Brasília, DF: $\mathrm{MEC} / \mathrm{SEF}$.

CORBO, Olga. Seção Áurea: um contexto para desenvolver a noção de incomensurabilidade de segmentos de reta. Dissertação (Mestrado em Educação Matemática) - PUC, São Paulo, 2005.

.Um estudo sobre os conhecimentos necessários ao professor de matemática para a exploração de noções concernentes aos números irracionais na educação básica. Tese (Doutorado em Educação Matemática). UNIBAN, São Paulo, 2012.

DANTAS, Wildes Gonçalves. Os saberes e concepções acerca das práticas dos professores de Matemática dos anos finais do Ensino Fundamental em escolas públicas do Estado de São Paulo em um processo de implementação do currículo. Dissertação (Mestrado em Educação Matemática) - UNIBAN, São Paulo, 2010.

FISCHBEIN, Efraim; JEHIAN, Ruth; COHEN, Dorit. The concept of irrational numbers in high-school students and prospective teachers. Educational Studies in Mathematics, Boston: Kluwwer Academic Publishers, n. 29, p. 29-44, 1995. 
GRENCHI, Wanderlei Aparecida. Percepções de professores da rede pública estadual de São Paulo acerca do ensino da matemática num contexto de mudança curricular. Dissertação (Mestrado em Educação Matemática) - UNIBAN, São Paulo, 2011.

PIETROPAOLO, Ruy Cesar. Parâmetros Curriculares de Matemática para o Ensino Fundamental. Educação Matemática em Revista, São Paulo: SBEM, edição especial, ano 9, n. 11A, p. 34-38, abr, 2002.

RODRIGUES, Rosineide Monteiro. Os desafios da formação continuada de professores que ensinam matemática no Ensino Médio em um cenário de reorganização curricular. Dissertação (Mestrado em Educação Matemática) - UNIBAN, São Paulo, 2010.

SÃO PAULO (Estado). Secretaria de Estado da Educação. Proposta curricular do Estado de São Paulo: Matemática. Coordenação de Maria Inês Fini. São Paulo: SEE, 2008.

Caderno do Professor: matemática, ensino fundamental $-8 .^{\mathrm{a}}$ série $/ 9 .{ }^{\circ}$ ano 1. ${ }^{\circ}$ bimestre. Coordenação: Maria Inês Fini; equipe: Nilson José Machado, Carlos Eduardo de Souza Granja, José Luiz Pastore Mello, Roberto Perides Moisés e Walter Spinelli. São Paulo: SEE, 2009.

Processo de promoção por merecimento do quadro de magistério. Prova Professor de Educação Básica II e Professor de Matemática. 2010. Disponível em: $<$ http://site.cesgranrio.org.br/eventos/concursos/seesp0109/pdf/provas3Dia/ Prova\%20Matematica\%20PEB\%20II_completa.pdf >. Acesso em: 30 jan. 2012.

SHULMAN, Lee. S. Knowledge and teaching: foundations of the new reform. Harvard Educational Review, 57 (1), p. 1-22, 1987.

SIROTIC, Natasa. Prospective secondary mathematics teachers' understanding of irrationality. Dissertação (Mestrado) - Simon Fraser University, Canadá, 2004. 